\title{
Stress triaxiality to evaluate the effective distance in the volumetric approach in fracture mechanics
}

\author{
B. El Hadim ${ }^{1}$, H. El Minor ${ }^{2}$ \\ ${ }^{1}$ (Department of Mechanics / CRMEF, Settat, Morocco) \\ ${ }^{2}$ (Research Team MMS / ENSA, Agadir, Morocco)
}

\begin{abstract}
The distribution of stress triaxiality is determined in the vicinity of notch defect performed in the specimen submitted to compression load. The calculations are carried out by using $3 D$ finite element analysis. The evaluation of notch stress intensity factor is made by using the volumetric approach. A new method to evaluate the effective distance in this approach is proposed.
\end{abstract}

Keywords: Stress triaxiality, notch defect, stress intensity factor, volumetric approach and effective distance.

\section{Introduction}

In fracture mechanics, the critical stress intensity factor or so called fracture toughness and other mechanical proprieties are measured in some conditions of geometry, loading mode and constraint. So, they have to be applied in the same conditions. The transferability of these proprieties is imperative in structural design because change of geometry or constraint conditions may promote brittle fracture. This transferability is based on the stress triaxiality which takes into account the tridimensional stress field. In this paper, $\beta$ is used as a measure of stress triaxiality. This parameter is defined as the ratio of the hydrostatic stress over the equivalent Von Mises stress:

$$
\beta=\frac{\sigma_{h}}{\sigma_{e q, V M}}
$$

Where:

$$
\sigma_{h}=\frac{\sigma_{x x}+\sigma_{y y}+\sigma_{z z}}{3}
$$

And:

$$
\sigma_{e q, V M}=\frac{1}{\sqrt{2}} \sqrt{\left(\sigma_{1}-\sigma_{2}\right)^{2}+\left(\sigma_{1}-\sigma_{2}\right)^{2}+\left(\sigma_{1}-\sigma_{2}\right)^{2}}
$$

It is well known that ductile fracture is sensitive to the stress triaxiality. There are several indicators to quantify the state of constraints at defect tip in the literature. Over the list of these indicators, one can quote the T-Stress [1], the Q parameter [2], the multiaxiality parameter [3] and the $p$ parameter [4].

The evaluation of notch stress intensity factor is made by using the volumetric approach which supposes that the fracture process requires a certain fracture volume. This volume is assumed as a cylinder with effective distance at its diameter. In this paper, we propose a new method based on stress triaxiality to evaluate the effective distance.

\section{Material}

The material studied is high-strength steel $45 \mathrm{CrMoSi} 6$ according to the French standard. Its mechanical and chemical proprieties are listed in Table I and Table II.

Table I

Chemical proprieties of $45 \mathrm{CrMoSi} 6$

\begin{tabular}{|c|c|c|c|c|}
\hline \hline $\mathrm{C}$ & $\mathrm{Mn}$ & $\mathrm{Si}$ & $\mathrm{Cr}$ & Mo \\
\hline 0.45 & 0.6 & 1.6 & 0.6 & 0.25 \\
\hline \hline
\end{tabular}

Table II

Mechanical proprieties of $45 \mathrm{CrMoSi} 6$

\begin{tabular}{c|c|c|c|c|c|}
\hline \hline $\begin{array}{c}\mathrm{E} \\
(\mathrm{GPa})\end{array}$ & $v$ & $\begin{array}{c}\sigma_{\mathrm{Y}} \\
(\mathrm{MPa})\end{array}$ & $\begin{array}{c}\sigma_{\mathrm{U}} \\
(\mathrm{MPa})\end{array}$ & $\mathrm{A} \%$ & $\begin{array}{c}\text { Density } \\
\left(\mathrm{kg} / \mathrm{m}^{3}\right)\end{array}$ \\
\hline 210 & 0.28 & 1463 & 1662 & 2.8 & 7800 \\
\hline \hline
\end{tabular}

\section{Geometrical Characteristics}

Tests were performed using U-notched circular specimens (Fig.1) with the external radius $\mathrm{Re}=20 \mathrm{~mm}$, internal radius $\mathrm{Ri}=10 \mathrm{~mm}$, thickness $\mathrm{B}=7 \mathrm{~mm}$, and the notch length $\mathrm{a}=4 \mathrm{~mm}$. Different notch radii were obtained using a wire-cutting electrical discharge machine (EDM) [5]. Four notch radii are considered: $\rho=0.3, \rho=0.5$, 
$\rho=1.0$ and $\rho=2.0 \mathrm{~mm}$. The specimens are submitted to compression load in order to determine the critical loads when the fracture occurs. These loads are introducing to the simulation computation to finally evaluate the critical notch stress intensity factor and the stress triaxiality evolution.
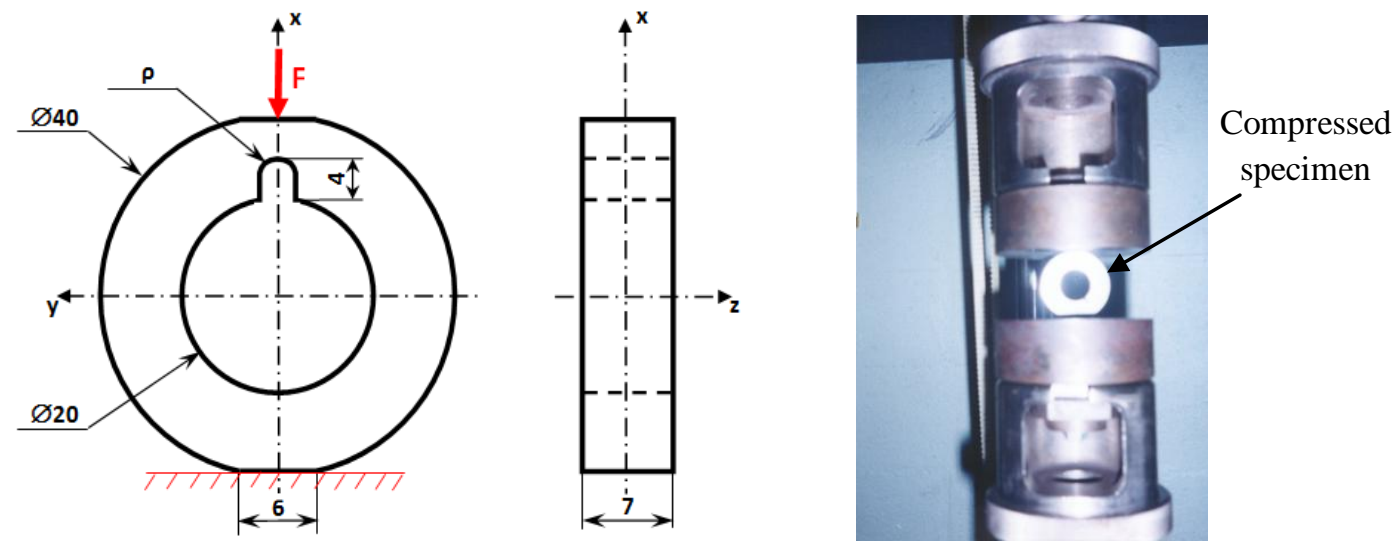

Fig.1. Specimen geometry and compression load.

IV. Notch Stress Intensity Factor And Volumetric Method

Stress distributions around the notch defect have been converted into so called notch stress intensity factor using the notch fracture mechanics and particularly the volumetric method.

The volumetric method [6] is a local fracture criterion, which supposes that the fracture process requires a certain fracture volume. This volume is assumed as a cylinder with effective distance at its diameter.

The elastic-plastic stress distribution along the ligament is plotted in the bi-logarithmic diagram as can be seen in Fig.2:

Three distinct zones in the diagram can be distinguished:

- Zone I: the elastic-plastic stress opening stress increases and attains a peak value.

- Zone II: the elastic-plastic stress drops gradually in the elastic regime.

- Zone III: starts at a certain distance which is named the effective distance. It represents linear behaviour in the bi-logarithmic diagram.

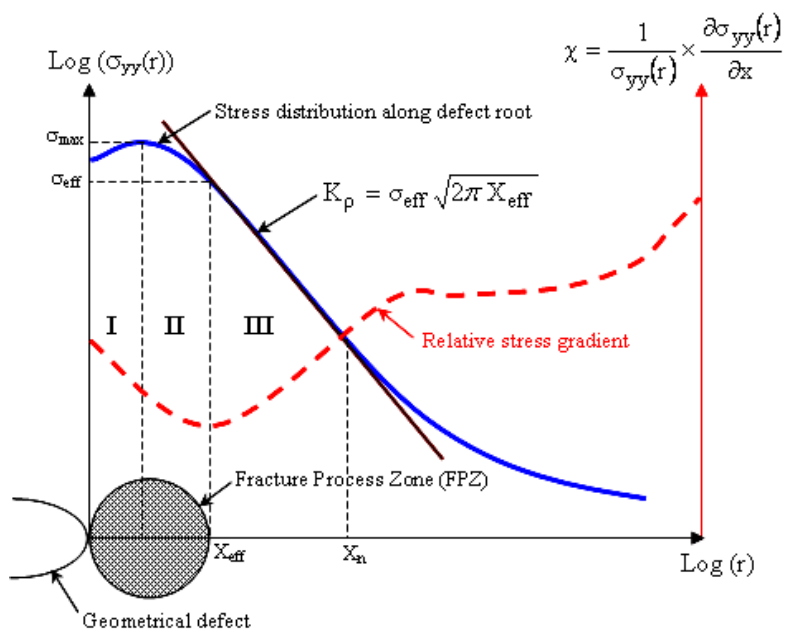

Fig.2. Schematic elastic-plastic stress distribution along notch ligament and stress intensity concept.

The notch stress intensity factor [N.S.I.F] is defined as function of effective distance and effective stress:

$$
K_{\rho}=\sigma_{e f f} \sqrt{2 \pi X_{e f f}}
$$

The effective distance corresponds to the minimum of the relative stress gradient which given as:

$$
\chi(r)=\frac{1}{\sigma_{y y}(r)} \frac{\partial \sigma_{y y}(r)}{\partial r}
$$

The effective stress is considered as the 
average volume of the stress distribution over the effective distance. However stresses are multiplied by a weight function in order to take into account the influence of stress gradient due to geometry and loading mode. The effective stress is defined as:

$$
\sigma_{e f f}=\frac{1}{X_{e f f}} \int_{0}^{X_{e f f}} \sigma_{y y}(r) \times(1-r \times \chi(r)) d r
$$

\section{Finite Element Analysis}

The part modelled in 3D analysis is meshed by quadrangular elements with eight nodes. Computing was carried out on Castem software 2014 [7].

By using the maximum hoop stress as failure criterion [8], the stress distribution was simulated front of the notch (Fig.3) in the opening fracture mode.
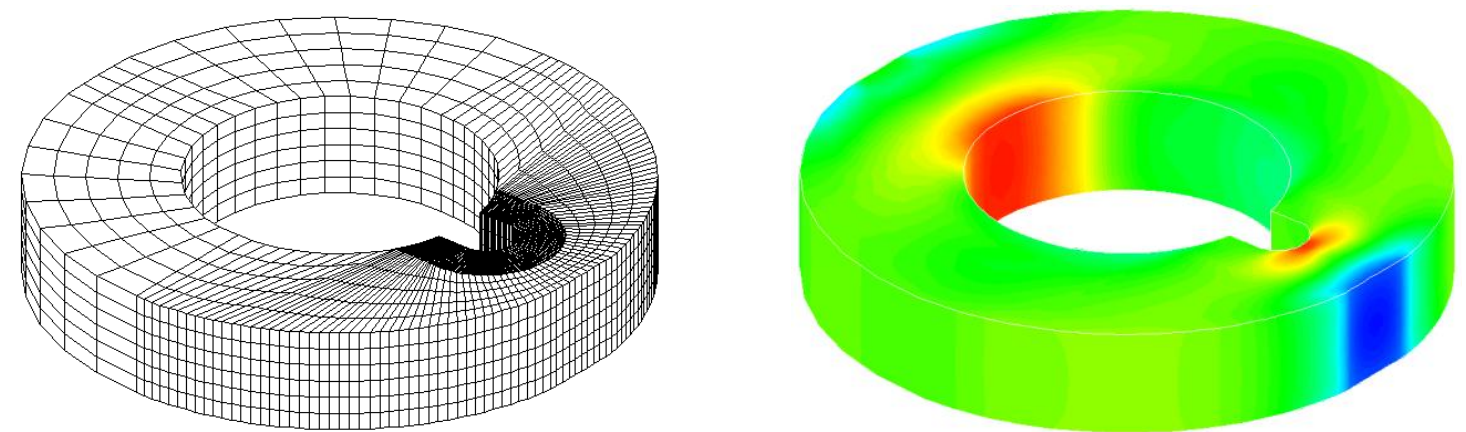

Fig.3. Mesh density and stress concentration in specimen.

The results of numerical simulations exhibit that for all notch radii, the hoop stress $\sigma_{\theta \theta}$ which is maximal at the middle of the notch, is predominant (Fig.5). Then, we will be interested in the radial direction in the middle of specimen where the crack is expected to occur first [9] and grow up radially (Fig.4).

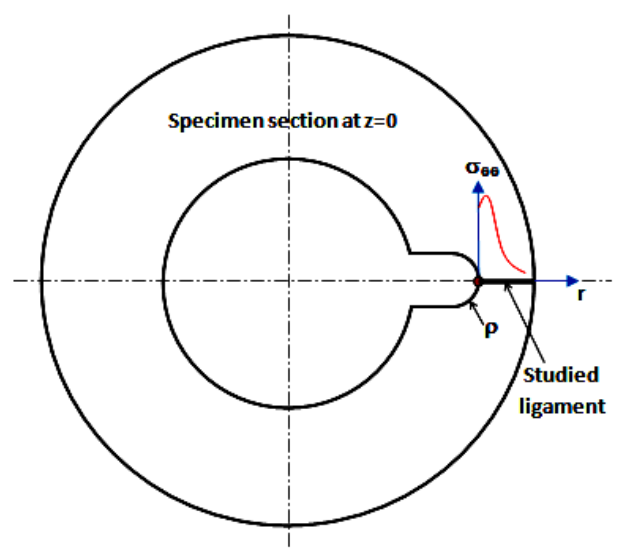

Fig.4. Studied ligament in the notch tip of specimen.

The stress evolutions are plotted versus the notch tip distance for each radius (Fig.5). The maximum stress values decrease when the notch radius increases. 

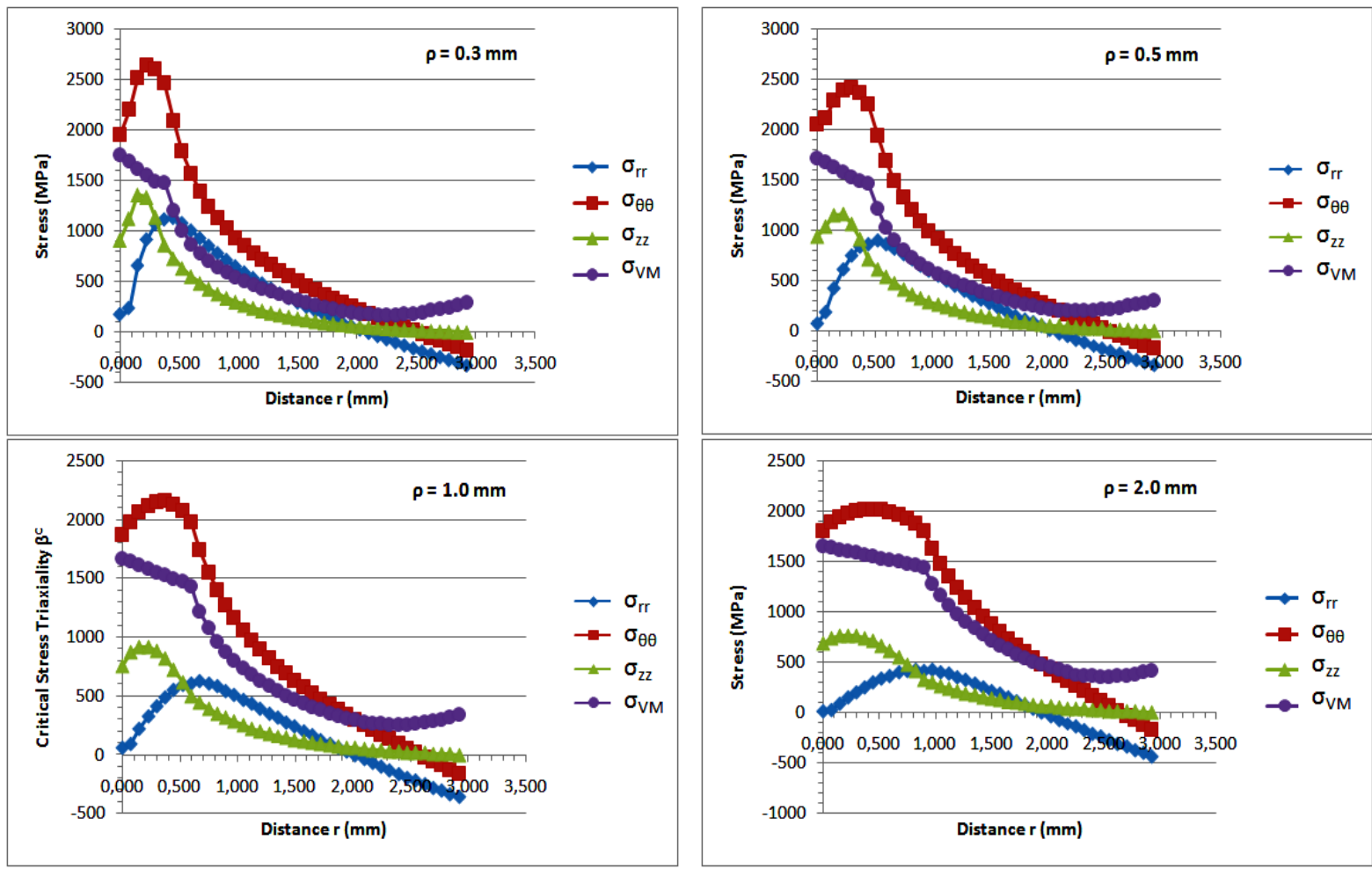

Fig.5. Stress distributions in the notch tip ligament.

\section{Results}

The critical notch stress intensity factor (C.N.S.I.F.) noted $K_{\rho}^{c}$ is computed by using the critical loads leading to the fracture specimens [5]. The critical effective distance $X_{\text {eff }}^{c}$ and the associated critical effective stress $\sigma_{e f f}^{c}$ are given by numerical simulations. These two characteristics are taken into account to determine the C.N.S.I.F. $K_{\rho}^{c}$ by using the relation (2). The results are summarized in table III.

Table III

Critical Notch Stress Intensity Factor for various notch radii

\begin{tabular}{|c|c|c|c|}
\hline \hline $\begin{array}{c}\text { Notch radius } \\
\rho(\mathrm{mm})\end{array}$ & $\begin{array}{c}\text { Critical effective stress } \\
\sigma_{\text {eff }}^{c}(\mathrm{MPa})\end{array}$ & $\begin{array}{c}\text { Critical } \\
\text { effective distance } \\
X_{\text {eff }}^{c}(\mathrm{~mm})\end{array}$ & $\begin{array}{c}\text { Critical notch stress } \\
\text { intensity factor } \\
K_{\rho}^{c}\left(\mathrm{MPa} \cdot \mathrm{m}^{0.5}\right)\end{array}$ \\
\hline 0.30 & 1961.670 & 0.375 & 95.221 \\
\hline 0.50 & 1895.018 & 0.450 & 100.765 \\
\hline 1.00 & 1744.737 & 0.600 & 107.126 \\
\hline 2.00 & 1782.460 & 0.825 & 128.333 \\
\hline \hline
\end{tabular}

The evolution of the relative stress gradient along the notch tip ligament is given in Fig.6 for each considered radius. The critical effective distance $X_{\text {eff }}^{c}$ corresponds to the minimum of relative stress gradient, as mentioned in section IV. All effective distances and associated effective stresses are reported above, in table III.
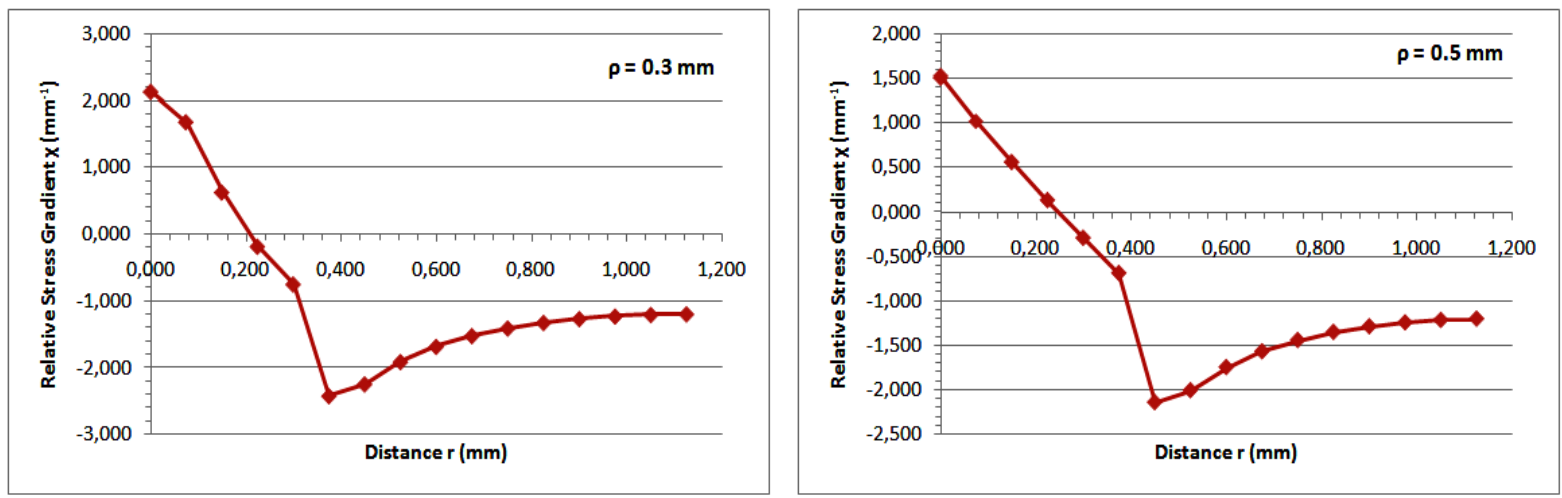

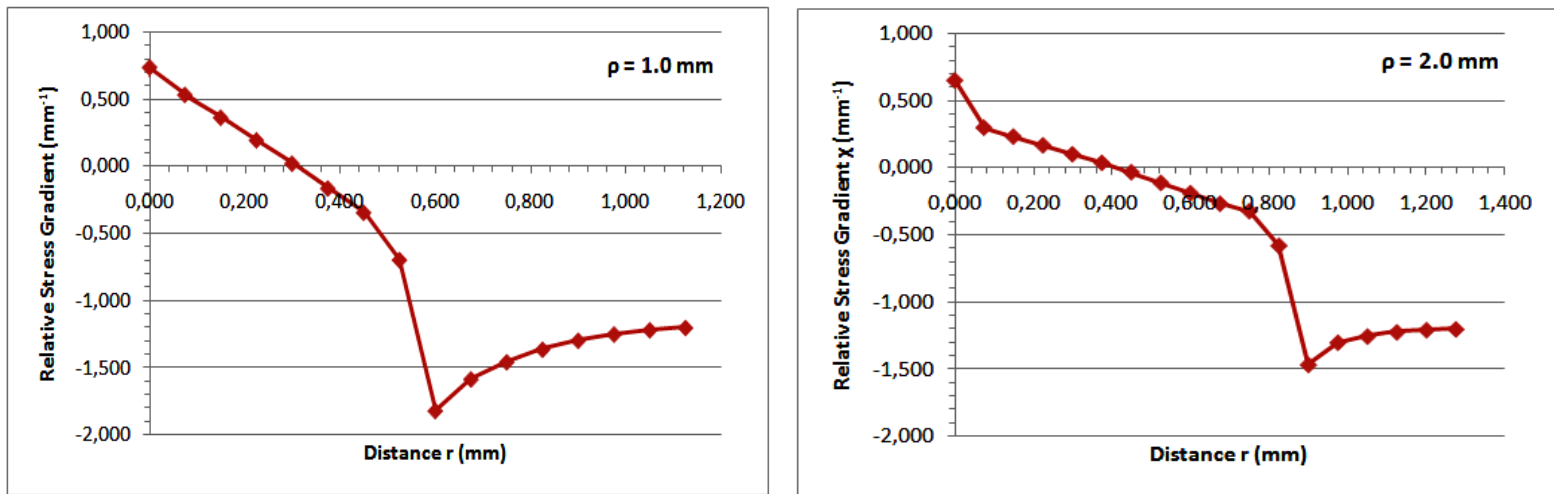

Fig.6. Relative stress gradient distributions in the notch tip ligament.

The stress triaxiality evolutions along the ligament are shown in Fig.7. These curves present two convex forms with an intersection in a point $(M)$. It is proven that this intersection point is at a distance $d_{M}$ on the ligament which corresponds to the effective distance $X_{e f f}^{c}$ (Table IV). One can conclude that the stress triaxiality can be used to determine the effective distance as that can be made with the relative stress gradient. The effective distance is then:

$$
X_{e f f}^{c}=d_{M}
$$

Where the point $M$ is located at a distance $d_{M}$ and defined as:

$$
\left\{\begin{array}{l}
\lim _{r \rightarrow d_{M}} \frac{d \beta}{d r}>0 \\
\lim _{r \rightarrow d_{M^{-}}} \frac{d \beta}{d r}<0
\end{array}\right.
$$

Table IV

Comparison of distance $d_{M}$ with effective distance $X_{\text {eff }}^{c}$.

\begin{tabular}{|c|c|c|}
\hline \hline Angle & effective distance & distance \\
$\rho(\mathrm{mm})$ & $X_{\text {eff }}^{c}(\mathrm{~mm})$ & $d_{M}(\mathrm{~mm})$ \\
\hline 0.30 & 0.375 & 0.375 \\
\hline 0.50 & 0.450 & 0.450 \\
\hline 1.00 & 0.600 & 0.600 \\
\hline 2.00 & 0.825 & 0.875 \\
\hline \hline
\end{tabular}

According to the figure below, we can also note that the amplitude of the critical maximum of triaxiality decreases when the notch radius increases.
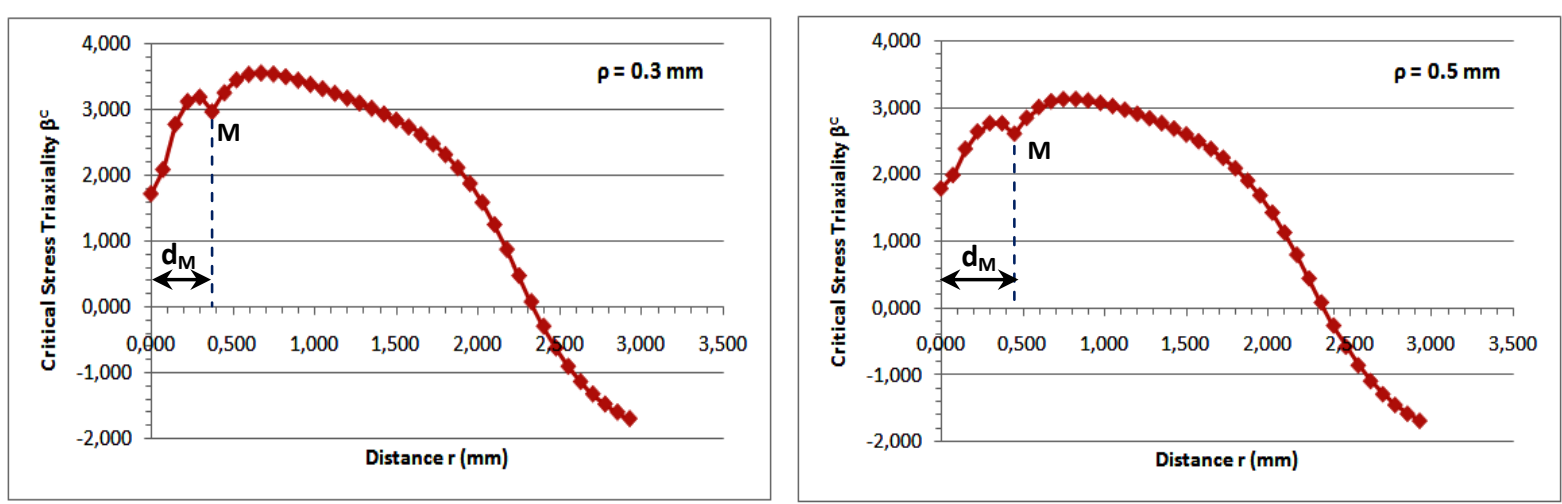

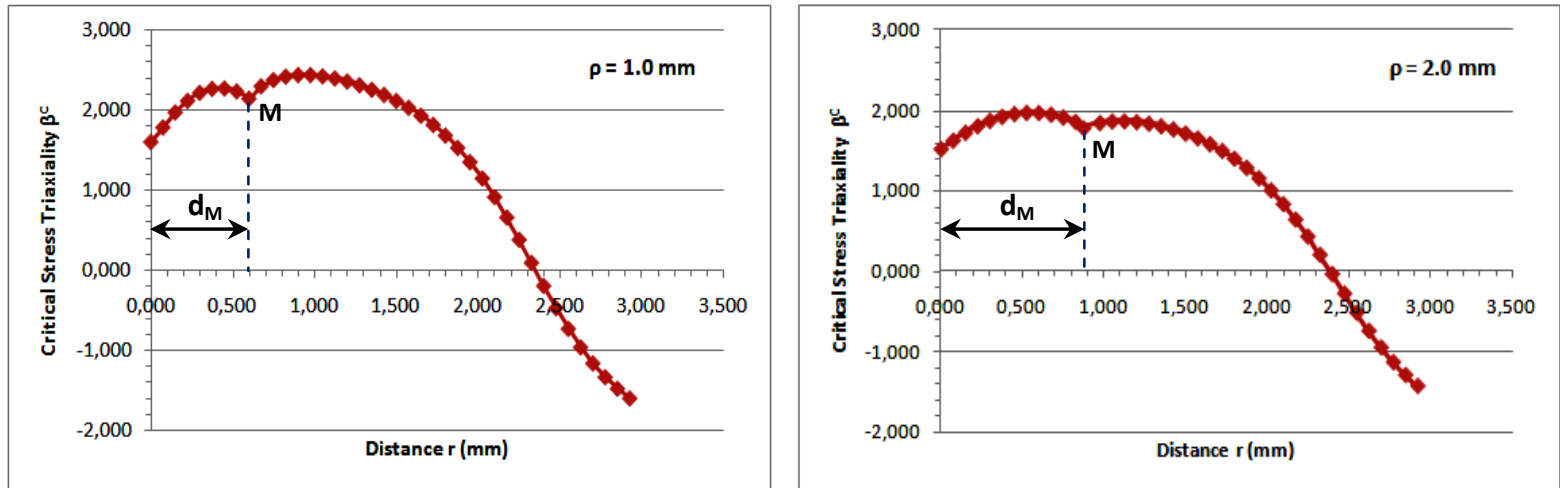

Fig.7. Critical stress triaxiality evolutions in the notch tip ligament.

\section{Conclusion}

The volumetric approach requires the determination of the diameter of fracture elaboration zone and the associated stress in the bilogarithmic diagram to evaluate the notch stress intensity factor. That is made by numerical computation of the effective distance $X_{e f f}^{c}$ and effective stress $\sigma_{e f f}^{c}$. The maximum tangential stress is used as fracture criterion. In order the take into account the tridimensional stresses; the evolution of stress trixiality $\beta$ is studied along the notch tip ligament. The stress triaxiality curves reveal two convex forms whose point of intersection is located at a distance noted $d_{M}$ which proved to be equal to the effective distance $X_{e f f}^{c}$. One can conclude that stress triaxiality can be used to determine the diameter of fracture elaboration zone in volumetric approach. In other words, the value of the effective distance can be obtained from the stress triaxiality is equal to $d_{M}$.

\section{References}

[1] C. Betegon, J. W. Hancock, Two parameter characteristics of elastic-plastic crack tip fields, J. Appl. Mech. 58, pp. 104-101, (1991)

[2] N.P. O’Dowd, C.F. Shih, Family of crack tip fields characterized by a triaxiality parameter I: Structure of fields, J. Mech. Phys. Solids; 39, pp. 898-1015, (1991).

[3] H. Clausmeyer, K. Kussmaul, E. Roos, Influence of stress state on the failure behaviour of cracked components made of steel, ASME, Appl. Mech. Rev. 44 (2), pp. 77-92, (1991).

[4] O. Akourri, I. Elayachi, Stress Triaxiality as Fracture Toughness Transferability Parameter for Notched Specimens, International Review of Mechanical Engineering, (2007).

[5] H. El Minor, Rupture fragile en mode mixte amorcée à partir d'entaille, Thèse de Doctorat, Université de Rabat, Morocco, (2002).

[6] G. Pluvinage, Fracture and Fatigue emanating from stress concentrators (Dordrecht: Kluwer Academic Publishers; 2003).).

[7] Castem 2014, Logiciel d'éléments finis développé par le département des études mécaniques et thermiques du commissariat français de l'énergie atomique C.E.A, France.

[8] B. El Hadim and col. , Evaluation of Notch Stress Intensity Factor in pipe with external oriented defect, International Review of Mechanical Engineering, Vol.5 N1, pp. 7-11, January (2011).

[9] B. El Hadim and col., Fracture toughness transferability in pipe with external oriented defect, International Review of Mechanical Engineering, Vol.5 N5, pp. 804-811, July (2011). 